\title{
El proceso extractivista y los paradigmas de desarrollo. Un abordaje inicial al caso de la apropiación de las aguas del río Atuel
}

Gustavo Gastón Pérez ${ }^{1}$

\section{RESUMEN}

El conflicto por el río Atuel es una puja de larga data. Pero el conflicto no debe reducirse al mero enfrentamiento político entre dos provincias vecinas, en el caso que nos ocupa, La Pampa y Mendoza. Las controversias no reconocen fronteras jurisdiccionales. Los territorios son escenarios de disputas de poder entre diferentes sujetos sociales. La apropiación de los recursos naturales comunitarios por parte de determinados sujetos en detrimento de otros conforma una de las problemáticas más complejas de las relaciones sociales. Los impactos territoriales en el área de los humedales del Atuel en ambas provincias continúan como consecuencia del despojo del recurso hídrico. Las concepciones de extractivismo y desarrollo son sumamente esclarecedoras para entender este proceso. Por lo tanto, el objetivo que se plantea en este artículo es analizar desde una perspectiva crítica el caso de apropiación de caudales de las aguas del río Atuel y sus impactos territoriales actuales, a partir de autores que realizan un abordaje de los procesos extractivos y de los paradigmas de desarrollo.

Palabras clave: Río Atuel; extractivismo; desarrollo; apropiación; impactos territoriales.

1 Facultad de Ciencias Humanas, Universidad Nacional de La Pampa. Mail de contacto: gustavoperez24@ gmail.com 


\begin{abstract}
The conflict over the Atuel River is a longstanding struggle. But the conflict should not be reduced to the mere political confrontation between La Pampa and Mendoza. Disputes do not recognize jurisdictional boundaries. The territories are the setting of power conflicts among different social subjects. The appropriation of communal natural resources by certain subjects to the detriment of others constitutes one of the most complex problems of social relations.

The territorial impacts on the Atuel wetlands area in both provinces continue as a result of the dispossetion of water resources. The conceptions of extractivism and development are very enlightening to understand this process. Therefore, the aim of this article is to analyze from a critical perspective the appropriation of the water flows of the Atuel river and its current territorial impacts, based on authors who approach the subject from the extractive processes and development paradigms.
\end{abstract}

Keywords: Atuel River; extractivism; development; appropriation; territorial impacts.

Fecha de recepción: 10/12/2019

Fecha de aceptación: 12/06/2020 


\section{El proceso extractivista y los paradigmas de desarrollo. Un abordaje inicial al caso de la apropiación de las aguas del río Atuel}

\section{INTRODUCCIÓN ${ }^{2}$}

Las políticas de Estado vinculadas con el desarrollo, la planificación y el ordenamiento territorial tienen una trayectoria signada por diversas miradas y enfoques de acuerdo a las conceptualizaciones y contextos de cada momento histórico. Por supuesto, esas perspectivas están atravesadas por decisiones políticas e ideológicas que implican, más allá de nuevas propuestas teóricas, formas de abordaje que aún perduran en los lineamientos estatales y tienen impactos sobre el espacio.

En el presente trabajo se adscribe a la concepción de espacio geográfico entendido como una instancia de la totalidad social (Santos, 1996, 2000), es decir producto de las relaciones sociales, a la vez que productor de los procesos, en continua reconstrucción. Las manifestaciones espaciales imbuidas de historicidad de los procesos sociales, en retroalimentación, son el campo de abordaje actual de la ciencia geográfica (Santos, 1990) ${ }^{3}$.

Asimismo, otro concepto fundamental de la Geografía es el de territorio. Territorio concebido como una porción del espacio mediado por desiguales relaciones de poder espacializadas entre diversos sujetos sociales. En la permanente construcción social de los territorios y las multiterritorialidades, se visibilizan claramente conflictos entre los distintos individuos y grupos por una multiplicidad de factores (Haesbaert, 2013). En la problemática por las aguas del río Atuel los procesos conflictivos se materializan en los desplazamientos forzados, la expulsión de pobladores rurales de sus tierras por la carencia de un recurso (agua) apropiado por otros sectores de mayor poder económico y político, sus cambios en los modos de vida, la degradación ambiental del entorno, entre otras variables (Gaviño Novillo, 2012; Dillon y Comerci, 2015).

El río Atuel (Figura 1) es uno de los afluentes meridionales del sistema Desaguadero-Salado-Chadileuvú-Curacó-Colorado cuya cuenca es la de mayor superficie desarrollada íntegramente en la República Argentina (Gaviño Novillo, 2012). Tiene sus nacientes en la provincia de Mendoza, en la cordillera de los Andes, a escasos kilómetros del límite internacional con Chile (Difrieri, 1980). El río Atuel posee un módulo de $34 \mathrm{m3} / \mathrm{s}$, se extiende por una superficie de drenaje de $39.404 \mathrm{~km}^{2}$ y se desarrolla entre los paralelos $34^{\circ}$ y $35^{\circ}$ de latitud Sur y entre los meridianos de $70^{\circ}$ y $67^{\circ}$ 30' de longitud Oeste (Gaviño Novillo, 2012). En el territorio pampeano, la subcuenca del río Atuel se delimita por el oeste con la meseta basáltica, al sur con la prolongación de esa área mesetaria y por el este con la cuenca del propio río Desaguadero (Gaviño Novillo, 2012).

2 El presente artículo se enmarca en el Proyecto de Investigación "Geografías de La Pampa: dinámica, conflictos y sinergias multiterritoriales y multiescalares", dirigido por la magíster Beatriz Susana Dillon y acreditado mediante Res. 165-CD-2020, de la FCH-UNLPam. Asimismo, constituye el resultado de las primeras investigaciones del autor en el marco de la convocatoria de Becas de Posgrado para iniciar Doctorados y Maestrías de la UNLPam (Res. 098-2019 del Consejo Superior).

3 Idea elaborada a partir de Santos (1990, pp. 132-133). 
Figura 1. Mapa de localización del río Atuel.

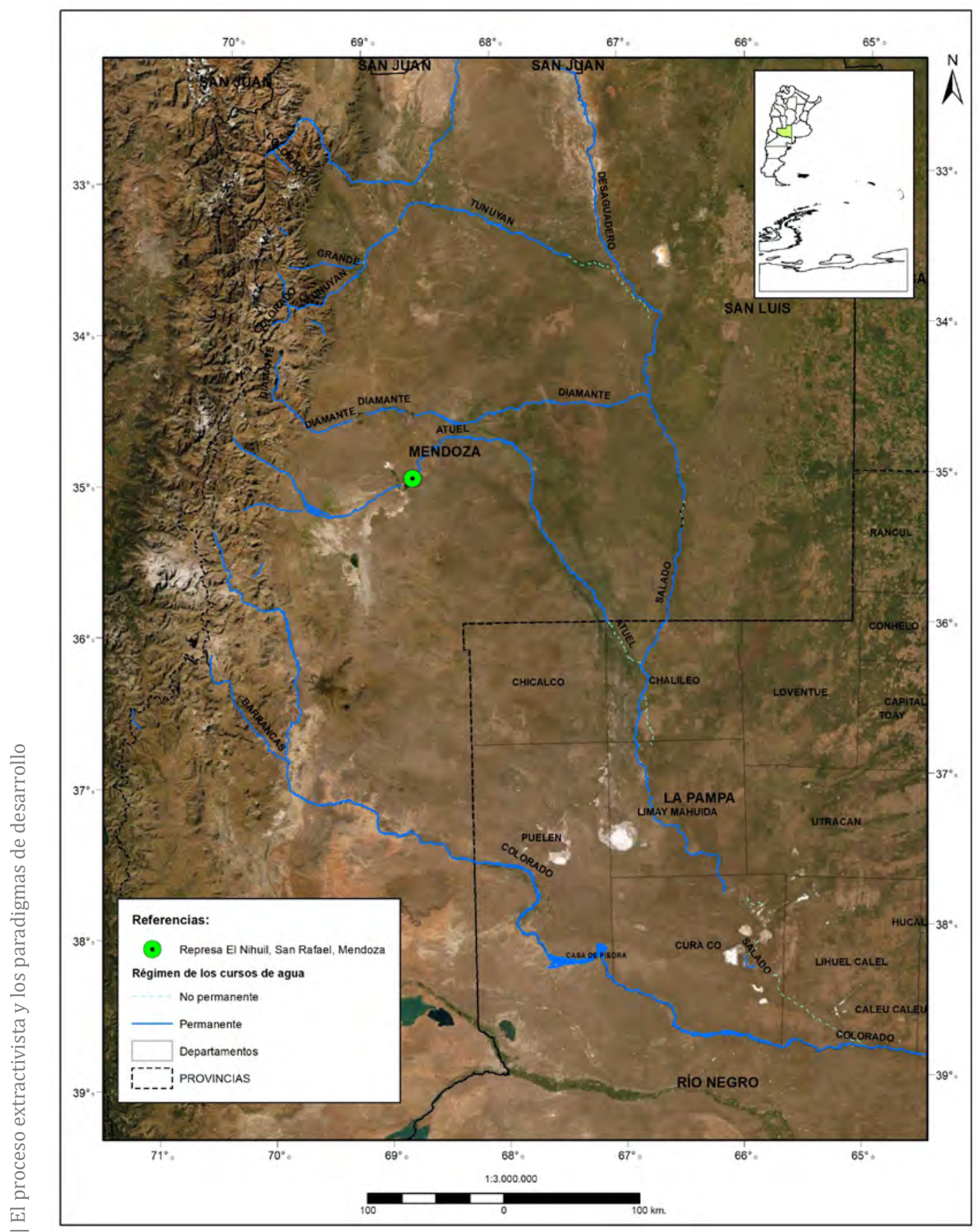

Fuente: Juan Pablo Bossa, 2020.

Desde una perspectiva geográfica, el sector occidental de la provincia de La Pampa se caracteriza por la dominancia del monte bajo de jarillal, en un ambiente dominado por la aridez. Es un espacio de tránsito surcado por huellas y picadas de traza 
irregular y poco densa (Comerci, 2008). El subespacio de la depresión fluvial AtuelSalado-Chadileuvú-Curacó se encuentra en el espacio pastoril de La Pampa según la clasificación socioeconómica propuesta por Covas (1998).

El espacio pastoril posee escasas localidades, parajes y puestos distribuidos en el área rural. La actividad predominante es la ganadería caprina y bovina extensiva en una superficie de aproximadamente un tercio del total provincial, pero con menos de $5 \%$ de la población total de La Pampa (Covas, 1998). Asimismo, en este espacio se encuentra la mayor cantidad de hogares con necesidades básicas insatisfechas (Comerci, 2008). La mayoría de los pobladores del Oeste pampeano son descendientes de pueblos originarios, y aquellos que se dedican a la actividad productiva rural se denominan puesteros o crianceros. Estos son productores familiares que habitan puestos que garantizan su producción-reproducción, aunque poseen dificultades para acumular excedentes y poca disponibilidad de procurarse recursos productivos y financieros (Comerci, 2008).

Los humedales o bañados del río Atuel se localizaban en el sudeste mendocino y noroeste pampeano, incrementando su superficie en la intersección del Atuel con el río Salado. Los humedales se desvanecieron progresivamente durante el último siglo debido a los usos unilaterales e indiscriminados del agua en el denominado oasis sur de la provincia de Mendoza, precisamente en un área vulnerable y expuesta a alteraciones ambientales por hallarse en la denominada diagonal árida que atraviesa América del Sur.

El agua dulce en el mundo es un recurso estratégico, y Latinoamérica, y Argentina en particular se destacan por poseer importantes reservas, como así también de grandes yacimientos hidrocarburíferos, lo que llevó a Acosta (2009) a denominar este proceso como 'la maldición de la abundancia', referido a los crecientes conflictos y tensiones en torno al uso y manejo de los recursos hídricos y minerales. En este sentido, como expresa Seoane (2013, p. 109) en la compilación Extractivismo, despojo y crisis climática, "el agua constituye un bien común natural con características distintivas y especiales: su existencia y el acceso a la misma resultan vitales para la producción y la reproducción de la vida sobre la tierra [...] Su disponibilidad y libre acceso remiten a un derecho particularísimo: el derecho a la vida".

La mentada crisis del agua a nivel global y su 'escasez' nos invitan a reflexionar en torno a estas formulaciones y cuestiones asociadas a estos fenómenos con los que guardan directa relación, tales como: las enormes dificultades para un número importantísimo de población que no puede acceder a ella, los patrones de consumo vinculados a modelos de desarrollo que priorizan su uso con fines agrícolas e industriales, la privatización y mercantilización del agua, la deficiente gestión de los recursos hídricos por parte de empresas y Estados, entre otras variables que limitan el consumo doméstico y comunitario. Como sostiene Dillon (2018, p. 895):

[...] la escasez es funcional al modelo capitalista, tal como lo es la desigualdad. Pero la escasez no es una cuestión inherente a las cosas o a los bienes, la escasez es una relación social con las cosas y con los bienes; una cuestión y acción ideológica y estrictamente económica. 
Antecedentes por usos indiscriminados de los recursos hídricos se pueden encontrar no solo en Argentina sino también en el resto del mundo. Por citar solo algunos de ellos se puede mencionar el caso del lago Chad en África o el desecamiento del mar Aral debido al aprovechamiento de los ríos que abastecen a ese lago del Asia Central, los litigios internacionales por el uso de las aguas de los ríos Éufrates o Jordán, entre otros conflictos por los recursos hídricos (Méndez, 2011).

En el caso del río Atuel, el aprovechamiento en la provincia cuyana de Mendoza data desde finales del siglo XIX. El momento determinante del cese de caudales en el sur mendocino y noroeste pampeano se concretó con la construcción del dique y complejo hidroeléctrico Los Nihuiles en 1947 (Figura 1), obra aprobada, financiada y ejecutada por el gobierno nacional. A partir de allí y durante 25 años, el río no escurrió por territorio pampeano. Desde la década de 1980 y hasta la actualidad los caudales ingresados en La Pampa son esporádicos e intermitentes y representan una escasa o nula escorrentía que impiden el acceso de las poblaciones ribereñas (Cazenave, 2012). A pesar de la provincialización de La Pampa en 1952 o el fallo de la Corte Suprema de Justicia de la Nación de 1987 que declaró la interprovincialidad del río, no se ha logrado que se respeten los derechos de las poblaciones al agua como derecho humano fundamental y particularísimo, pues implica en últimas instancias, el derecho a la vida.

El conflicto por las aguas del río Atuel es una puja de larga data, más de un siglo si se toma como referencia el primer corte del arroyo Atuel viejo, que atravesaba la localidad de Santa Isabel, entre los años 1917 y 1918 (Cazenave, 2012). Pero el conflicto no debe reducirse al mero enfrentamiento político entre dos provincias vecinas, en el caso que nos ocupa, La Pampa y Mendoza. Las controversias no reconocen fronteras jurisdiccionales. Los territorios son escenarios de disputas de poder entre diferentes sujetos sociales. La apropiación de los recursos naturales comunitarios por parte de determinados sujetos en detrimento de otros conforma una de las problemáticas más complejas de las relaciones sociales.

Los impactos territoriales en el área de los humedales del Atuel en ambas provincias continúan como consecuencia de la apropiación y del despojo del recurso hídrico. Esos impactos provocados en el ambiente, las comunidades urbanas, y los puesteros y campesinos ribereños al río, generaron procesos de desertificación, emigración, desarticulación socio-cultural, obstáculos para desarrollar actividades productivas y un descenso en el bienestar de la población (Gaviño Novillo, 2012; Dillon y Comerci, 2015).

¿Por qué se produce un proceso de acaparamiento de las aguas del Atuel que convierte al río en su cuenca inferior en un cauce seco de arena y sal? ¿Qué concepciones de desarrollo de los territorios trasuntan en la toma de decisiones sobre la creación de emprendimientos productivos? ¿Estamos ante un proceso de profunda extracción o explotación del recurso hídrico que afecta gravemente a poblaciones y territorios? Si bien en el marco de este artículo no podremos abordarlos a todos ellos, inicialmente, una hipótesis preliminar, orienta la búsqueda de respuestas en los procesos de apropiación y uso (y abuso) de los bienes comunes en el marco de un paradigma extractivo de recursos de la naturaleza y concepciones de desarrollo que traen aparejadas fuertes disparidades territoriales y falta de integración regional. 
Las concepciones de extractivismo y desarrollo son sumamente esclarecedoras para entender el proceso de apropiación del río Atuel. La ecología política y la geopolítica de los recursos naturales, como campos de conocimiento y problematización, también nos proporcionan sustanciales aportes para comprender este tipo de procesos extractivos que claramente impactan de manera desigual sobre los territorios, estableciendo diferenciaciones regionales que perduran hasta la actualidad. Pero a los efectos de este artículo, los lineamientos de ambos campos, ecología política y geopolítica, no serán abordados.

Por lo tanto, el objetivo que se plantea en este artículo es analizar desde una perspectiva crítica el caso de apropiación de caudales de las aguas del río Atuel y sus impactos territoriales actuales. La reflexión que se propone en este artículo constituye una etapa inicial del proyecto de investigación. Para ello, en consideración de los interrogantes y el objetivo explicitados, se propone un abordaje del conflicto a partir de una revisión bibliográfica de autores que realizan un análisis teórico de los procesos extractivos y de los paradigmas de desarrollo. Además, se presenta un análisis de datos demográficos censales para dar cuenta de los impactos poblacionales provocados por el corte del río Atuel en La Pampa.

\section{EXTRACTIVISMOS Y PARADIGMAS DE DESARROLLO: ABORDAJES TEÓRICOS}

Los vínculos entre extractivismo y determinadas concepciones de desarrollo, aunque inicialmente puedan parecer contradictorios, son muy cercanos, pues numerosas políticas de planificación del desarrollo se han consolidado en Argentina y América Latina en base a procesos intensivos de explotación de recursos naturales. Si bien no hay una definición unívoca de extractivismo, de manera tradicional y en términos generales se lo reconoce como un proceso que implica la extracción de recursos naturales, sobre todo de origen mineral (aunque no sea su único origen) y con un destino específico y mayoritario que es la exportación con escaso o nulo procesamiento (Gudynas, 2013). Desde la perspectiva de Féliz (2012, p. 3), el "extractivismo histórico remite a una particular modalidad de la producción que supone -en principio- la utilización de las riquezas naturales (o bienes comunes) a un ritmo que no es compatible con los tiempos de reposición impuestos por la naturaleza". Asimismo, Féliz (2012, p. 4), incorpora dos dimensiones sumamente relevantes para entenderlo como un proceso que implica "la transformación de los bienes comunes en mercancías y la generación de rentas extraordinarias vinculadas al monopolio de la propiedad sobre esos bienes y su destino hacia la exportación".

Por su parte, Seoane (2013) incluye una perspectiva del extractivismo en el marco de una crisis profunda y estructural del sistema capitalista. En el proceso extractivista se incluyen actividades tales como la megaminería, las guerras del agua, la explotación de hidrocarburos y el monocultivo de soja, en el marco de los agronegocios, con severos impactos sociales y ambientales. Además, se visibiliza una emergencia y profundización de conflictos y tensiones entre sujetos sociales con intencionalidades e intereses contrapuestos (Seone, 2013).

En este sentido, Merlinsky (2017, p. 222) asevera que "los conflictos ambientales se originan a partir de disputas políticas en torno a los modos diferenciados de producción, apropiación, uso, y significado de los bienes naturales". Estos procesos 
de índole estructural se intensifican por la profunda mercantilización de los bienes comunes naturales como el suelo, el agua y los minerales. Incluso desde perspectivas más amplias, los procesos extractivistas reúnen actividades y prácticas sociales como los enclaves turísticos, las pasteras y la implantación industrial de árboles que consolidan una misma lógica de devastación ambiental y despojo material y simbólico (Seoane, 2013).

En los últimos años se han repensado también nuevas definiciones respecto a extractivismo y neoextractivismo. Svampa y Viale abordan este último concepto y sostienen:

Podemos caracterizar al mismo [(neo)extractivismo] como un patrón de acumulación basado en la sobreexplotación de bienes naturales, cada vez más escasos, en gran parte no renovables, así como en la expansión de las fronteras de explotación de territorios antes considerados como improductivos (Svampa y Viale, 2014a, p. 28).

Los autores enfatizan en el carácter global de nuevas actividades que podrían encuadrarse bajo este abanico conceptual, así como también en la fuerte tendencia a la mercantilización de volúmenes cada vez mayores de recursos de la naturaleza. La intensificación de esta dinámica requiere cada vez de mayores recursos, fundamentalmente materia y energía, presionando sobre bienes naturales y territorios, bajo un marco denominado 'Consenso de los commodities', al decir de Svampa (2012), parafraseando al Consenso de Washington que se impuso durante el periodo neoliberal.

De este modo, el neoextractivismo, abarcaría entonces otras actividades más allá de las tradicionalmente consideradas como extractivas, tales como los monocultivos o la megaminería a cielo abierto, la expansión de la frontera petrolera y energética (a través de técnicas como el fracking), la construcción de grandes represas hidroeléctricas, y la expansión de la frontera pesquera y forestal, entre otras actividades (Svampa y Viale, 2014a).

Asimismo, es significativo subrayar que Gudynas (2011) incorpora algunos otros rasgos al neoextractivismo, como una mayor presencia estatal, la consolidación de una inserción internacional supeditada y subordinada a las relaciones globales de poder y del mercado, el afianzamiento de enclaves y fragmentaciones territoriales, y el incremento de los impactos sociales y económicos. Este 'neoextractivismo progresista' propuesto por Gudynas (2011), como proceso político y económico de explotación de recursos naturales, encuentra puntos de anclaje en los modelos neodesarrollistas (Féliz, 2017), que sucedieron al neoliberalismo, como proyectos estratégicos de los gobiernos latinoamericanos posneoliberales.

El (neo)desarrollismo se conformó en Argentina como estrategia de la nueva clase hegemónica surgida del neoliberalismo. La clase dominante (gran capital local), conducida por su fracción hegemónica (gran capital trasnacionalizado), consiguió articular a través del Estado un programa de políticas públicas que permitieran canalizar productivamente las tensiones que surgen del desarrollo capitalista en la era posneoliberal (Féliz, 2012, p. 9).

Con respecto a los paradigmas de desarrollo, inicialmente, debemos destacar que luego de la segunda posguerra, el concepto de desarrollo se incorpora a la 
agenda internacional en el marco de un mundo cambiante y del contexto geopolítico de la Guerra Fría (de Souza Santos, 2014). Los procesos y dimensiones sobre los que operó esta teorización del desarrollo fueron variados: la pobreza, el tercer mundo, la ausencia de tecnología y capitales suficientes, el rápido crecimiento demográfico, prácticas agrícolas consideradas arcaicas, valores culturales y étnicos identificados como 'atrasados'. El 'aparato discursivo del desarrollo' acuñó términos como iletrados, subdesarrollados, entre otros, que se convirtieron, dentro de esta racionalidad, en instrumentos de poder y control (Pintos, 2018). Es decir, nos encontramos ante un modelo excluyente de múltiples sectores sociales que concibe al desarrollo bajo un modelo aplicativo de 'arriba hacia abajo', etnocéntrico y tecnocrático, con un enfoque universalista y uniformizador del desarrollo. Tal como se puede observar, por ejemplo, en la propuesta determinista de Rostow sobre las etapas de desarrollo desde las sociedades tradicionales hasta llegar a la sociedad de consumo 'deseada' luego de atravesar una serie de fases evolucionistas ${ }^{4}$ (Pintos, 2018).

Estos lineamientos generales tuvieron una fuerte influencia en la planificación del desarrollo económico y social para América Latina, a partir de la consolidación de la denominada Alianza para el Progreso (AP) en 1961. Es dable aclarar el contexto en el que esta alianza se consolidó a nivel regional. La planificación durante los '50, concebida como un procedimiento idóneo para racionalizar el proceso de decisiones requeridas para la ejecución de un determinado proyecto político (De Mattos, 1986), no era bien recibida por los gobiernos latinoamericanos de entonces pues subyacía una connotación negativa de ella que aludía a los procedimientos del sistema soviético. El 'miedo' al comunismo, en un marco de relaciones geopolíticas mundiales dominadas por la Guerra Fría, la mayor presencia estadounidense en los asuntos latinoamericanos, entre otros factores, comienza a configurar concepciones sobre la planificación y el desarrollo 'aceptables' para los gobiernos locales de manera progresiva a partir de la década del '60 que, con la irrupción mencionada de la AP otorga legitimidad a una proliferación de organismos de planificación, con un perfil claramente racional y normativo (De Mattos, 1986).

Por otro parte, es importante destacar como el sistema capitalista, en su versión global actual, profundiza rasgos y características propios de su composición, acrecentando las disparidades territoriales, la subalternización de grupos sociales, y la centralización de bienes, capitales y recursos. Dillon y Comerci (2015) sostienen en su libro Territorialidades en tensión en el Oeste de La Pampa que el capitalismo global produce una renovada territorialidad con fuertes tendencias a la concentración del capital, excedentes y recursos, en palabras de David Harvey (2004), la generación de una 'acumulación por desposesión'. En este proceso de despojo, las autoras destacan consecuencias como:

(...) la mercantilización extrema de los recursos, la privatización de la tierra y la expulsión forzosa de las poblaciones campesinas, la conversión de diferentes formas de derechos de propiedad colectiva en derechos de propiedad exclusivos, la supresión del derecho a

4 En relación a la teoría de Rostow y su posible "aplicación" en América Latina (AL), resulta interesante el abordaje de A. Almandoz (2008) en su texto "Despegues sin madurez" en el que analiza de manera crítica el vínculo entre industrialización, urbanización y desarrollo en AL, y los factores por los cuáles resultó inconducente la "aplicabilidad" del modelo en AL. 
los bienes comunes, la transformación de la fuerza de trabajo en mercancía y la disminución de las formas de producción y consumo alternativas, entre otros factores (Dillon y Comerci, 2015, p. 18).

Las disputas por el control de los espacios y los recursos configuran territorialidades en tensión que se expresan en las luchas por la tierra, por el agua, por los recursos de la naturaleza, en síntesis, por los bienes comunes que pertenecen a los pueblos.

En este punto, es importante señalar los aportes de Svampa y Viale (2014b) que destacan las voces críticas en torno a la creencia del crecimiento infinito en el marco de un supuesto desarrollo de las sociedades, proceso que entraña expandir al máximo de los límites de extracción sobre la naturaleza en el marco de un proceso de acumulación del capital global. En este sentido, los autores enfatizan en la incompatibilidad de este sistema extractivo de un modelo económico fundado en el crecimiento continuo.

A continuación, se aborda de modo exploratorio el caso del conflicto por las aguas del río Atuel, en clave del proceso extractivista, y el modelo de desarrollo que se implementó a mediados del siglo pasado para el manejo de cuencas hídricas en la provincia de Mendoza.

\section{EL CONFLICTO POR EL RÍO ATUEL: ¿UN CASO DE EXTRACTIVISMO? ${ }^{5}$}

En términos generales, en la utilización y explotación de los recursos naturales ha primado una visión mercantilista por sobre las condiciones socioculturales de los territorios y sus poblaciones. Y esa privación no solo afecta materialidades, por el escaso y nulo escurrimiento de las aguas del río, sino también aspectos inmateriales por los fuertes impactos causados en las prácticas sociales y culturales de las comunidades, que debieron adaptarse a sobrevivir en contextos de precariedad y vulnerabilidad, sin el recurso vital para la vida cotidiana.

Las desiguales relaciones de poder se materializan en el espacio a través de disparidades regionales, a partir de la toma de decisiones de los diferentes sujetos sociales, y también se manifiestan de manera inmaterial a partir de la situación de subordinación de los sectores marginados por las prácticas extractivas. Distintas entidades estatales (nacional y provincial, como el Departamento General de Irrigación de Mendoza) junto al capital nacional y transnacional, constituyen los actores políticos y agentes económicos con mayor peso e influencia. Estos actores son determinantes al momento de aplicar supuestas políticas de desarrollo que despliegan en el territorio enclaves de producción (oasis sur mendocino) en detrimento de vastas áreas de la cuenca inferior. De este modo, se configura territorialmente una periferia interna y regional que forma parte de una periferia mayor, estatus que le fuera conferido a la Argentina en el marco de la división internacional del trabajo, como mero productor

5 El abordaje del conflicto por el río Atuel y sus impactos territoriales contiene una profusa bibliografía. Para mencionar solo algunas de ellas podemos destacar los estudios institucionales llevados a cabo por la UNLPam (2005 y 2012), abordajes desde el campo de las leyes (Scovenna, 2012 y Aguirre, 2015), aportes de ONG como la Fundación Chadileuvú -Fuchad- (Testimonios de los ríos robados, 2018), e investigaciones académicas (González y Hernández, 2010; Dillon y Comerci, 2015; Rojas y Wagner, 2016; Langhof et al, 2017, entre otros), que se citan en las referencias bibliográficas. 
de materias primas y commodities en base a una economía extractiva de recursos de la naturaleza con nulo o escaso valor agregado.

En contextos donde se consolida la idea de la 'crisis mundial del agua' es sustancial advertir que la supuesta crisis debería interpretarse como una problemática que atañe a las políticas de gestión de agua, más que problemas por su supuesta escasez. El acaparamiento del agua, en el marco de la desigual distribución del recurso, implica para extensos territorios tanto la falta de acceso para consumo de comunidades o campesinos, así como también, procesos de desertificación de vastas áreas por las que dejan de escurrir corrientes fluviales y disminuye la calidad de sus aguas subterráneas.

Por lo tanto, para el caso del río Atuel, se conforman procesos de fragmentación territorial entre territorios insertos en la economía del capital bajo la lógica de oasis bajo riego y territorios no irrigados, 'desérticos' y abandonados, que no entran en la lógica del capital. Estos procesos han sido calificados por Dillon (2018) como el 'círculo vicioso de la apropiación del agua', convirtiendo al recurso hídrico en un bien material mercantilizado a expensas de su rol como elemento vital y derecho humano fundamental de las personas, a partir de procesos de apropiación por parte de sectores concentrados de la economía que, con la anuencia del Estado, organizan procesos de 'colonialismo hídrico' (Dillon, 2018, p. 898).

Sin embargo, el caso del río Atuel no es el único que puede identificarse en el país. Otros cursos fluviales y sus poblaciones adyacentes también sufren las consecuencias de la falta de gestión integrada de los recursos hídricos o las deficiencias de los comités de cuencas para administrar los recursos y moderar las tensiones entre las provincias. La cuenca del río Desaguadero-Salado-Chadileuvú (que no posee comité) tanto en la provincia de San Luis como en La Pampa misma, ha sido objeto, de igual manera, de usos inconsultos por parte de las provincias de Mendoza y San Juan de los cursos afluentes que fluyen hacia el otrora gran colector Desaguadero, alguna vez navegable. Esos usos unilaterales han provocado graves procesos de desertificación ambiental y emigración de población. Los ríos que fluían al Desaguadero como el San Juan, Mendoza, Tunuyán, Diamante o el mismo Atuel hoy solo son 'cicatrices hídricas' (Difrieri, 1980) de arena y sal en su parte terminal. Los usos en las cuencas superiores y medias concentran las actividades productivas y económicas como la agricultura bajo riego y agroindustrias, la producción de energía hidroeléctrica y el turismo en las ciudades capitales o mayores. Mientras que aguas abajo, o cauces secos abajo, solo queda fragmentación, marginalidad y vulnerabilidad socio-ambiental.

En el departamento Lavalle, por ejemplo, al norte mendocino, el corte del río Mendoza para usos en el oasis norte sumado a condiciones naturales de aridez ha provocado la desertificación de vastas áreas no irrigadas ${ }^{7}$. Proceso de desertificación no solo entendido en su dimensión ambiental sino también con implicancias socio-económicas sobre todo en las condiciones de vida de los puesteros del espacio

6 En referencia a la cuenca del Desaguadero-Salado se recomienda el "Estudio Integral de la cuenca del río Desaguadero-Salado-Chadileuvú-Curacó" de la Facultad de Ingeniería de la UBA (2009) y el artículo de González y Pratts, 2016.

7 Al respecto se puede consultar una amplia bibliografía sobre el proceso de desertificación del sector no irrigado del departamento Lavalle en Mendoza, entre las que se puede mencionar Grosso Cepparo (2013, 2015 y 2017), Rubio (2014), Laura Torres (2008, 2010), Abraham y otros (2014), Salomón y otros (2008). 
rural. Los estudios apuntan a poner en discusión la naturalización de la escasez de los recursos hídricos como un problema 'de todos' (Grosso Cepparo, 2017) y no en la gestión de los recursos por parte de las instituciones, lo que crea y construye configuraciones territoriales diferenciales entre quienes tienen acceso o no al agua. Para ejemplificar esta situación, en Mendoza, las tierras irrigadas constituyen el 4,8 \% de la superficie provincial, mientras que en ella se aglutina el $95 \%$ de total poblacional. En particular, "de los 10.224 km² del territorio de Lavalle, solo el 3,3 \% se halla bajo riego y concentra el $90 \%$ de la población" (Grosso Cepparo, 2017, p. 33).

Por último se puede mencionar el caso del río Pasaje-Juramento-Salado, perteneciente a la gran cuenca del Paraná-Plata, que si bien cuenta desde hace varias decenios con un comité de cuenca que integran las provincias de Catamarca, Tucumán, Salta, Santiago del Estero y Santa Fe, en las últimas décadas no estuvo exenta de tensiones entre las dos últimas provincias debido a las captaciones de agua en su cuenca media e inferior.

Retomando el conflicto del río Atuel, De Mattos (1986) nos ilumina respecto a los problemas que entrañó la planificación regional para repensar el caso objeto de estudio. Ellos son, por un lado, las disparidades regionales y la concentración territorial de las actividades y la población en nodos o enclaves territoriales. Por otro lado, la escasa integración económica y territorial entre ciertas regiones de la periferia y los centros dinámicos de cada sistema. Ambos procesos pueden identificarse en el caso del río Atuel.

Cuando el Estado Nacional, junto al gobierno de la provincia de Mendoza deciden a mediados del siglo pasado llevar a cabo aprovechamientos productivos, que implicaron fuertes inversiones en infraestructura, como incremento de áreas bajo riego para frutihorticultura y vides, producción de energía hidroeléctrica y, posteriormente, turismo vinculado a actividades hídricas, consolidaron un escenario jurídico y político que ya era desigual. La Pampa no se convertiría en provincia hasta el periodo 1951-1952 (cuando por status político, económico y demográfico podría haberlo sido desde inicios del siglo XX), pues quien debía velar por los derechos de los ciudadanos territorianos era el Estado nacional, máxime cuando ya se habían generado protestas de pobladores locales en la década del '30 ante las interrupciones de dos de los tres arroyos que penetraban en La Pampa, el Atuel propiamente dicho y el arroyo Butaló (Difrieri, 1980). Solo quedaría activo el arroyo de La Barda, que finalmente cesaría su escorrentía permanente en forma definitiva en 1947 con la creación del embalse y central hidroeléctrica de Los Nihuiles.

Es decir, recuperando el análisis de De Mattos (1986), el Estado Nacional, junto a los sucesivos gobiernos provinciales mendocinos y los sectores privados que comenzaron a invertir y beneficiarse de la infraestructura aportada por el Estado, consolidaron procesos de concentración de las actividades productivas en enclaves territoriales, en este caso San Rafael y General Alvear, en detrimento del propio sureste mendocino y noroeste pampeano, generando amplias disparidades regionales y convirtiendo a los espacios mencionados en vastos territorios degradados y olvidados.

Entre los impactos territoriales de la apropiación de las aguas del Atuel en el sudeste mendocino y en el noroeste pampeano se pueden destacar: carencia de agua para consumo doméstico y ganadero, procesos de desertificación, emigración de población, pérdida de biodiversidad, pauperización de las condiciones de vida, perjuicios 
al patrimonio local, pérdida de valores culturales asociados a la cultura hídrica, entre tantas otras (Dillon y Comerci, 2015). Estas privaciones las sufrieron y sufren hasta la actualidad las comunidades locales producto de la nula integración económica y territorial de estas periferias interiores de nuestro país.

Desde el punto de vista ambiental el reclamo por un caudal mínimo fluvioecológico ${ }^{8}$ apunta entre otras cosas, a recuperar, aunque sea paulatinamente los inmensos y riquísimos humedales de la conjunción de los ríos Atuel y Salado en territorio pampeano (área protegida de Ñochilei-có y Gran Salitral). Los bañados, desaparecidos en la actualidad, no solo contenían una gran biodiversidad biológica (faunística y florística) sino que también eran utilizados por los puesteros para desarrollar sus actividades productivas a través del aprovechamiento del agua, el suelo y las pasturas naturales para el ganado extensivo, base de su economía familiar.

En el plano demográfico los impactos han sido significativos. A la disminución de la población se adicionan los despojos de las tierras de los puesteros por un doble proceso (Scovenna, 2012). Por un lado, la carencia de agua apta para la sobrevivencia humana y el desarrollo ganadero que provocó el abandono de tierras y la emigración por parte de las poblaciones rurales. Por otro, los procesos de despojo forzado por valorización de tierras antes consideradas marginales y, revalorizadas en la actualidad, por el avance de las fronteras ganaderas y mineras, por parte de inversores nacionales y extranjeros. En muchos de esos despojos, no exentos de violencia material y simbólica, intervienen actores privados que ejercen presión sobre la tierra y la omisión de Estado que no resuelve la situación de fondo de la lucha y propiedad de la tierra (Scovenna, 2012).

El impacto sobre la población de los departamentos de la cuenca del Atuel y el Salado en La Pampa se refleja en los datos de los censos nacionales o territorianos de población ${ }^{9}$ (ver tabla 1).

Tabla 1. Evolución de la población de los departamentos Curacó, Chalileo, Chicalcó y Limay Mahuida entre 1920 y 2010.

\begin{tabular}{|l|c|c|c|c|c|c|c|c|c|c|}
\hline Dptos./Años & $\mathbf{1 9 2 0}$ & $\mathbf{1 9 3 5}$ & $\mathbf{1 9 4 2}$ & $\mathbf{1 9 4 7}$ & $\mathbf{1 9 6 0}$ & $\mathbf{1 9 7 0}$ & $\mathbf{1 9 8 0}$ & $\mathbf{1 9 9 1}$ & $\mathbf{2 0 0 1}$ & $\mathbf{2 0 1 0}$ \\
\hline Curacó & 1.120 & 1.644 & 1.259 & $\mathbf{1 . 5 0 4}$ & $\mathbf{8 8 7}$ & 834 & 995 & 878 & 886 & 1.039 \\
\hline Chalileo & 1.750 & 1.888 & 2.102 & $\mathbf{2 . 4 2 0}$ & $\mathbf{1 . 8 3 8}$ & 1.443 & 1.737 & 2.093 & 2.517 & 2.999 \\
\hline Chicalcó & 769 & 1.198 & 1.037 & $\mathbf{1 . 1 8 9}$ & $\mathbf{1 . 1 0 2}$ & 920 & 1.199 & 1.212 & 1.595 & 1.502 \\
\hline $\begin{array}{l}\text { Limay } \\
\text { Mahuida }\end{array}$ & 1.165 & 1.474 & 1.596 & $\mathbf{1 . 6 6 3}$ & $\mathbf{9 4 9}$ & 772 & 836 & 586 & 475 & 506 \\
\hline
\end{tabular}

Fuente: Acosta y otros (2013) en base a datos de Censos Nacionales de Población y Viviendas (CNPyV, 1947-2010) y Censos del Territorio Nacional de La Pampa (1920, 1935 y 1942).

No es el objetivo del presente artículo realizar un análisis exhaustivo de los datos censales sobre los departamentos de la cuenca en La Pampa, pero claramente

8 El estudio de la UNLPam (2005) determinó tres escenarios posibles para la recuperación del caudal mínimo fluvioecológico.

9 Para ver en detalle la variabilidad demográfica de los departamentos en los datos censales, ver Acosta y otros (2013). 
se observa que en los cuatro casos existió una drástica disminución entre 1947, año del corte total del río Atuel (Arroyo de la Barda) en La Pampa y los datos reflejados en el siguiente CNPyV del año 1960. Para Curacó y Limay Mahuida el decremento demográfico fue superior al 40\%, mientras que para Chalileo fue del $20 \%$ y Chicalcó poco más del 5\%. En todos los casos tomó varios decenios la recuperación de la población, excepto los departamentos de Limay Mahuida y Curacó, en dónde hasta la actualidad el volumen de la población aún no se ha recuperado. Debe mencionarse también, que los incrementos demográficos que hoy se avizoran se corresponden con áreas urbanas y no en zonas rurales, en dónde el despoblamiento ha sido continuo.

Asimismo, pueden visualizarse impactos sociales, en los modos de vida de los puesteros, muy bien descriptos por Comerci y Dillon (2015). En su análisis, las autoras destacan el daño sobre la dinámica socio-cultural de las formas de vida de los puesteros, cambios en sus estrategias productivas y en sus representaciones sociales. Esos impactos sobre la cotidianidad de sus prácticas (Comerci y Dillon, 2015, pp. 71-72) se traducen en carencias e incertidumbres relacionadas con la alimentación, el abastecimiento de agua, cambios en los modos de vida, desaparición de los usos recreativos del río y 'temores' vinculados con la imposibilidad de continuar con las actividades productivas y sus pautas culturales de producción y reproducción. En síntesis, consecuencias sociales que impactan fuertemente en las formas de vida, en la identidad cultural y en el patrimonio de las poblaciones ribereñas.

Recuperando la perspectiva analítica de Boaventura de Souza Santos (2014, p. 69), el autor reflexiona:

(...) el desarrollo se ha hecho más antisocial, más ligado que nunca al crecimiento, más dominado por la especulación financiera y más depredador del medioambiente. Los costos sociales del desarrollo se han vuelto cada vez más evidentes.

Evidentemente cuando se habla de desarrollo integrado de las cuencas hidrográficas $^{10}$, se omite señalar que el tan mentado 'desarrollo' de determinadas áreas ocurre en detrimento de otros espacios, a partir de la apropiación de los recursos de la naturaleza. Por ello es necesario construir teorías y propuestas de desarrollo alternativo en el que los actores principales sean las propias comunidades con el soporte técnico y económico de los Estados provinciales y nacional.

Según de Souza Santos (2012, p. 62) "el desarrollo alternativo está formulado con base en una crítica de fondo a la estricta racionalidad económica que inspiró el pensamiento y las políticas de desarrollo dominantes". Por lo tanto, plantea la subordinación de los intereses económicos a los políticos o, por lo menos, concebir la dimensión económica como una más de la múltiples dimensiones que implica el concepto de desarrollo concebido desde análisis alternativos. Esa multidimensionalidad subraya la relevancia de las variables políticas, socio-culturales y ambientales

10 Este modelo de planificación regional en AL comenzó a desarrollarse años antes de que se produjese la irrupción generalizada de la planificación nacional y corresponde a un enfoque de planificación intrarregional, esto es de una región considerada en forma aislada del resto de su contexto nacional. Esta forma de encarar la planificación regional tiene como antecedente directo los procedimientos y los resultados de la experiencia desarrollada por la TVA (Autoridad del Valle del Tennessee) desde 1933 en los Estados Unidos, en el marco de las políticas decididas por el Presidente Roosevelt con el propósito de hacer frente a las secuelas de la desocupación provocada por la gran crisis económica del '29 (De Mattos, 1986, p. 6). 
endógenas de los territorios en complementariedad de la dimensión económica, que contemplen la participación democrática, la diversidad cultural, las particularidades ambientales, los rasgos identitarios de los territorios locales. Un desarrollo alternativo concebido de esta manera supondría lograr mejores condiciones de vida para los sectores históricamente marginados, mayor autonomía y un empoderamiento ciudadano al incorporar a las comunidades en la toma de decisiones sobre su propia realidad.

Los atributos actuales del ordenamiento territorial presuponen políticas de Estado que articulen actuaciones públicas y privadas, sujetas a procedimientos políticos, técnicos y administrativos de la planificación, con medidas a mediano y largo plazo. En definitiva propone como fin ulterior el mejoramiento de las condiciones de vida de la población, intentando conciliar de manera coherente el desarrollo económico con integración territorial (Pintos, 2018).

Por el contrario, las decisiones tomadas en pos del desarrollo de áreas en detrimento de otras, entrañaron severos conflictos. Conflictos ambientales, que si bien en nuestro país se visibilizan como reacción a actividades extractivas tradicionales como minería y monocultivos, comienzan a avizorarse movimientos sociales de protesta y de resistencia, ante nuevas actividades extractivas como la técnica del fracking ${ }^{11}$, la megaminería, el acaparamiento de aguas, el uso masivo de agroquímicos, los despojos de tierras, entre otros.

Para el caso del Atuel, es muy importante destacar que las primeras protestas formales ante el acaparamiento del agua de los caudales de los arroyos o brazos Atuel y Butaló, datan de la década de 1930, a través de notas formales enviadas por productores del oeste pampeano al entonces gobernador del territorio nacional' ${ }^{12}, \mathrm{y}$ continuaron de manera ininterrumpida hasta la actualidad, por lo que estaríamos hablando de un conflicto ambiental que data de hace un siglo, si consideramos el primer corte o sustracción que provocó la desaparición del arroyo Atuel entre los años 1917 y 1918.

El conflicto tuvo más jalones a lo largo de su historia, que si bien no constituyen el propósito de este trabajo se mencionan solo algunos con el fin de dimensionar el proceso de apropiación. Entre ellos, la carta que envía el radiotelegrafista policial don Ángel Garay directamente al presidente Perón en 1947 desde Paso de los Algarrobos, describiendo el cuadro de situación, con familias enteras emigrando de las tierras resecas del Atuel, con sus pocas pertenencias, sus animales moribundos y hasta con casos extremos de niños fallecidos debido a la expansión de la difteria y las malas

11 El proceso extractivista en la cuenca del Atuel ha llegado hasta su paroxismo entre 2018 y 2019 cuando el gobierno provincial de Mendoza anunció que comenzaría a autorizar el 'desarrollo' de la técnica extractiva del fracking en la región de Malargüe, plena cuenca del Atuel. "Mendoza insiste con el fracking en el Río Atuel" Recuperado de: https://www.eldiariodelapampa.com.ar/index.php/edicion-digital/ locales/55476-mendoza-insiste-con-el-fracking-en-el-rio-atuel

12 “En la década de 1930 volvieron a producirse cortes ilegales en el curso sobre el brazo llamado Butaló, que motivaron airadas reacciones de los pobladores pampeanos, que llegaron a dinamitar los "tapones" en procura del libre escurrimiento del agua. Recién en esta oportunidad intervinieron autoridades nacionales a través de sucesivos organismos que realizaron informes técnicos claramente favorables al reclamo y señalando lo arbitrario de los sucesos. La provincia arribeña, si bien no le daba carácter oficial a estas construcciones de desvío, tampoco hacía nada por evitar la ilegalidad de estas obras, que disponían de los caudales a su antojo" (Scovenna, 2012, p. 83) 
condiciones de vida ${ }^{13}$. Este hecho causó tal impacto, que en 1949 se dicta la resolución N 50/49 de Aguas y Energía de la Nación, que solicitó a Mendoza tres sueltas anuales de una semana de duración cada una, régimen que conformaba solo el 2,7 \% del derrame anual del río. Sin embargo, ni siquiera eso lograron los pobladores del sur mendocino y noroeste pampeano, que a partir de allí estarían 25 años sin recibir una gota del recurso hídrico. Esta fue la primera resolución favorable a los reclamos de los pobladores, y también fue la primera en no cumplimentarse hasta la actualidad.

Luego se sucederían en el tiempo la obra o dique compensador Valle Grande en los '60, las ampliaciones de los Nihuiles, el incremento de las áreas bajo riego, el doble proceso de radicación de empresas y disminución de pequeños finqueros, con escasa capitalización para mantener sus producciones, el uso turístico de las aguas de río, entre otros usos.

Desde el punto de vista jurídico, se sustanciaría el primer juicio en el año 1979, que luego de ocho años de litigio, llegaría el recordado fallo de la Corte Suprema de Justicia de la Nación dictaminando la interprovincialidad del río Atuel, negada hasta el momento por las autoridades de la provincia cuyana. Acuerdos durante los '80 y '90 no tuvieron éxito alguno, y solo fueron remiendos a una situación de extractivismo que produjo el acaparamiento total del recurso. Ni el convenio marco de 2008 suscripto durante la presidencia de Cristina Fernández de Kirchner logró acercar las posiciones debido a los fuertes intereses del capital privado del regadío, y ciertos sectores políticos ligados a esos intereses.

Por último, en 2014 un nuevo juicio elevado ante el máximo tribunal de justicia por la provincia de La Pampa, intenta revertir una situación de despojo, que ha tenido en los últimos años de manera esperanzadora la movilización de vastos sectores de la sociedad y acciones colectivas que demuestran un mayor interés de las comunidades por sus propios bienes comunes. El daño ambiental y el agua como derecho humano fundamental son los ejes vertebradores de la demanda, que ya lleva cuatro años de idas y vueltas, pero que no impide a las poblaciones de los territorios vulnerados mantener en vilo sus estrategias de protesta y de resistencia.

Como sostienen Suárez y Ruggerio (2012) los conflictos ambientales colocan en tensión dos paradigmas o perspectivas. Por un lado, el desarrollo capitalista explotacionista, sea en su fase tradicional de extractivismo o actual de neoextracción, que incentiva la mercantilización del suelo, el saqueo de los recursos naturales y la exacerbación del consumo. Por otra parte, en contraposición, se plantea el paradigma de la sustentabilidad que si bien se ha convertido en un concepto superficialmente

13 En el libro Testimonios de los ríos robados (Fuchad) varios entrevistados que vivieron en el área ribereña manifiestan esta situación. Don Ángel Garay cuenta que estando en el Destacamento donde se desempeñaba como radiotelegrafista policial llega una mujer "con el chiquito en sus brazos, muerto, y dice: Mire oficial, se me murió el hijo de la peste que tenemos acá" (2018, p. 23). Asimismo lo afirma Don Basilio Cabral al describir la situación paupérrima ante la falta de agua y la muerte de animales relata: "Sí, morían niños y había peste, aunque le aclaro una situación particular que se daba con los chicos. Recuerdo que cuando la policía salía a recorrer la zona a caballo la gente escondía a los chicos. Esto lo hacían porque si los veían, les preguntaban a los adultos cómo los alimentaban; por eso los escondían. Si no podían alimentarlos los llevaban al Juez de Menores" (2018, p. 45). Por último, Doña Margarita Serraino, afirma sobre las muertes de niños: “A lo mejor ahí sí [en alusión a la zona de Paso de los Algarrobos] don Ángel Garay lo relató pero eso era por la gran peste de la difteria los pocos chicos que se salvaron fue por mi padre porque era el único que se animaba a entrar a las habitaciones y salvar a algunos" (2018, p. 61). 
sobreutilizado por sectores precisamente extractivistas abre la puerta a manifestaciones superadoras como pensar otras formas de desarrollo posible, las alternativas al desarrollo: el buen vivir, el sumak kawsay de los pueblos originarios en contra del despojo, la expoliación y exclusión de los sectores más vulnerables de la población.

Independientemente de los gobiernos que hayan detentado el poder tanto en América Latina como en Argentina en las últimas décadas, se recupera lo expresado en la introducción cuando se manifiesta que más allá de un periodo de centralidad del Estado en el ejercicio de ciertas políticas públicas, desde el punto de vista de la explotación de los recursos naturales se ha consolidado un patrón de explotación de los recursos naturales extractivo. Este paradigma neoextractivista (Svampa y Viale, 2014), con claro y sustancial apoyo de los Estados (neodesarrollismo, -Gudynas, 2013; Féliz, 2017) y liderado por las fuerzas del mercado tanto nacionales como transnacionales, enfatiza en la expoliación de recursos (agua, tierra, subsuelo) y refuerza un modelo de 'desarrollo' rígido en su estructura de acumulación y en la distribución social de ese 'crecimiento' (de Souza Santos, 2014).

Ello coloca en particular tensión, por un lado, los derechos ambientales de las comunidades y sus posibilidades de desarrollo territorial y, por otro lado, las políticas de crecimiento y concentración que llevan adelante los Estados y las corporaciones con el objetivo de obtener rentas y beneficios de la extracción de los bienes comunes de los pueblos. En el caso del río Atuel, se manifiesta en la concentración de actividades económicas y productivas como las agroindustrias, la generación de hidroenergía y el turismo en el llamado oasis sur de Mendoza en detrimento del propio sudeste mendocino y noroeste pampeano, mediante la apropiación total de los caudales del río.

\section{CONSIDERACIONES FINALES}

Los procesos extractivos implican la explotación intensiva y en grandes volúmenes de los bienes comunes naturales. Existen vínculos estructurales entre los modelos extractivos de desarrollo y las formas de la acumulación capitalista. Estos procesos se materializan en el espacio a través de conflictos ambientales a partir de las pujas y disputas entre los sujetos sociales en torno a la apropiación, uso y manejo de los bienes naturales. En el caso del río Atuel se visibiliza la apropiación de las aguas en una continuidad del proceso extractivo que aún perdura y provoca el despojo material y simbólico de las poblaciones ribereñas.

La carencia de agua por usos unilaterales altera los modos de vida y la supervivencia de las comunidades locales. En el caso del río Atuel, en el sureste mendocino y noroeste pampeano, se observan fuertes impactos, algunos de ellos irreversibles como la desaparición de los bañados, que lo convertían a fines del siglo XIX en uno de los humedales más extensos y ricos en biodiversidad del país. El daño ambiental infligido sobre el territorio y las poblaciones de la cuenca inferior es cuantioso e incalculable.

Alteración paisajística, desaparición de gran parte de la biodiversidad específica del humedal, emigración, empobrecimiento, descenso de los umbrales mínimos de bienestar, privación material e inmaterial de servicios ambientales, pérdida de patrimonio y efectos sobre la identidad cultural que provoca una 'amnesia cultural' o 
pérdida de la memoria hídrica. Estos son solo algunos de los severos impactos del proceso de acaparamiento de los recursos hídricos de la región.

Marcos legales e institucionales, con la anuencia y promovidos por los Estados nacional y provincial, han permitido y legitimado estas actividades extractivas en pos de un desarrollo con exclusión. Disparidades regionales y concentración territorial a través de economías de enclave han sido las marcas de origen de este tipo de planificaciones del espacio, aplicadas tecnocráticamente desde 'arriba hacia abajo' sin la más mínima participación ciudadana.

La falta de gestión integrada de las cuencas hídricas está provocando severos daños a los sistemas ecológicos de nuestro país, alterando de manera profunda los equilibrios ambientales que, en última instancia, son los que posibilitan la supervivencia de las poblaciones vulnerables y despojadas que viven de los recursos que provee la naturaleza.

Es un momento necesario y propicio para pensar alternativas al desarrollo tradicional. Ante la crisis civilizatoria que atravesamos, las políticas de gestión deben encaminarse a repensar los paradigmas vigentes, que sumergen a los territorios y poblaciones en la 'trampa' del desarrollo, desintegrado territorialmente y conformador de fuertes disparidades regionales entre áreas con un alto grado de inserción del capital, 'modernas' y adaptadas a los requerimientos del mercado, y áreas 'deprimidas', subdesarrolladas y periféricas.

En el caso que nos precede claramente podemos concluir que estamos ante un proceso de apropiación de recursos hídricos en manos de capitales privados que destinan su producción mayormente, aunque no solo, a la exportación de productos alimenticios, derivados y bebidas, con una fuerte complicidad del Estado que concesiona obras, infraestructuras y amplía áreas de riego, bajo tradicionales modelos de desarrollo de enclave territorial a expensas de fuertes desequilibrios regionales, concentración económica y empobrecimiento de ingentes sectores de población, persiguiendo solo un fin utilitarista y económico.

Para finalizar, el conflicto por el río Atuel es uno más de los tantos ejemplos en Argentina y América Latina del extractivismo de los recursos de la naturaleza, en este caso a partir de los usos unilaterales de recursos hídricos. Solo la acción organizada y colectiva de los pueblos podrá revertir, aunque sea parcialmente, estos procesos de despojo que destruyen territorios, culturas y vastas comunidades locales. 


\section{REFERENCIAS BIBLIOGRÁFICAS}

1. Acosta, A. (2009). La maldición de la abundancia. Quito, Ecuador: Ediciones de Abya Yala.

2. Acosta, M. et al (2013). “La enseñanza de problemáticas ambientales a escala local y regional. El caso de los humedales del río Atuel en el territorio pampeano". En Actas del IV Congreso Nacional de Geografía de Universidades Públicas y XI Jornadas Cuyanas de Geografía. Mendoza: UNCuyo.

3. Aguirre, E. (2015). El corte del río Atuel y sus implicancias jurídico penales: ¿y si estuviéramos frente a un delito ambiental? La Plata: Universitaria de La Plata.

4. Almandoz, A. (2008). “Despegues sin madurez. Urbanización, industrialización y desarrollo en la Latinoamérica del siglo XX". Revista EURE, Vol. XXXIV, No 102, pp. 61-76.

5. Cazenave, W. (2012). "El caso del río Atuel". En Scovenna, J. C. El caso del río Atuel desde la perspectiva de los derechos humanos. Santa Rosa: Pitanguá.

6. Covas, M. R. (1998). "Los espacios socioeconómicos de la provincia de La Pampa”. En Huellas № 3, Revista del Instituto de Geografía. FCH. UNLPam. Santa Rosa: UNLPam.

7. De Mattos, C. (1986). "Paradigmas, modelos y estrategias en la práctica latinoamericana de planificación regional". Pensamiento Iberoamericano, №10. Madrid: AECI/CEPAL.

8. de Souza Santos, B. (2012). De las dualidades a las ecologías. La Paz, Bolivia: Red Boliviana de Mujeres Transformando la Economía, REMTE.

9. de Souza Santos, B. (2014). Derechos humanos, democracia y desarrollo. Bogotá: Centro de Estudios de Derecho, Justicia y Sociedad, Dejusticia.

10. Dillon, B. y Comerci, M. E. (coord.) (2015). Territorialidades en tensión en el oeste de La Pampa. Sujetos, modelos y conflictos. Santa Rosa: EdUNLPam.

11. Dillon, B. (2018). “Las geografías del agua: extractivismo versus derecho humano. La situación en Argentina y en la provincia de La Pampa". En Cebrian Abellán. F.; Jover Martí, J. y Lois González, R. América Latina en las últimas décadas: procesos y retos. Cuenca: Ediciones de la Universidad de Castilla La Mancha.

12. Féliz, M. (2012). "Neoextractivismo, neodesarrollismo y proceso de acumulación de capital: ¿Superando el ciclo stop-and-go? Argentina, 2003-2012". VII Jornadas de Sociología de la UNLP, 5-7 de diciembre de 2012. La Plata. Recuperado de http://www.memoria.fahce. unlp.edu.ar/trab eventos/ev.1887/ev.1887.pdf

13. Féliz, M. y Torno, C. (comp.) (2017). El neodesarrollo en debate: crisis, transición y alternativas. Buenos Aires: El Colectivo.

14. Fundación Chadileuvú (2018). Testimonios de los ríos robados. Santa Rosa: Nexo Di Nápoli.

15. Gaviño Novillo, M. (2012). Estudio para la cuantificación monetaria del daño causado a la provincia de La Pampa por la carencia de un caudal fluvioecológico del río Atuel. Santa Rosa: Consultora de la Universidad Nacional de La Pampa.

16. Gobierno de la Provincia de La Pampa (1980). El Río Atuel es interprovincial. Tomos I a VI. Santa Rosa: Gobierno de La Pampa.

17. González, R. y Hernández, R. (2010). "Alteraciones socio-productivas generadas por las interrupciones de los ríos Atuel y Salado-Chadileuvú". En Dalmasso G., Camiletti, C. y Hernández, R. Libro del Tercer Congreso Pampeano del Agua. Santa Rosa: Base 1. Disponible en: www.lapampa.gov.ar/images/stories/Archivos/RecursosHidricos/Libro III Congreso del Agua.pdf).

18. Grosso Cepparo, M. V. (2017). “Agua y tierras secas: Lecturas críticas sobre la escasez hídrica en el departamento de Lavalle (Mendoza, Argentina)". Estudios Socioterritoriales, 22, pp. 27-45.

19. Gudynas, E. (2011). “El nuevo extractivismo progresista en América del Sur". En Acosta, A. y otros. Colonialismos en el siglo XXI. Barcelona: Icaria Editorial.

20. Gudynas, E. (2013). "Extracciones, extractivismos y extrahecciones: un marco conceptual sobre la apropiación de recursos naturales". Observatorio del Desarrollo, N ${ }^{\circ} 18$. CLAES. Recuperado de: http://ambiental.net/wp-content/uploads/2015/12/ GudynasApropiacionExtractivismoExtraheccionesOdeD2013.pdf 
21. Haesbaert, R. (2013). "Del mito de la desterritorialización a la multiterritorialidad". Cultura y representaciones sociales, vol. 8, No 15. UNAM: Ciudad de México. Recuperado de: http:// www.revistas.unam.mx/index.php/crs/issue/view/3383

22. Harvey, D. (2004). "El nuevo imperialismo: acumulación por desposesión". CLACSO: Buenos Aires. Recuperado de: http://biblioteca.clacso.edu.ar/clacso/se/20130702120830/ harvey.pdf

23. Langhoff, M. L., Geraldi, A. y Rosell, P. (2017). “El concepto de ciclo hidro-social aplicado a los conflictos por el acceso al agua. El caso de la disputa por el río Atuel entre las provincias de La Pampa y Mendoza, Argentina". Papeles de Geografía, 63, pp. 146-160. DOI: http:// dx.doi.org/10.6018/geografia/2017/280681 ISSN: 1989-4627

24. Méndez, R. (2011). El nuevo mapa geopolítico del mundo. Valencia: Tirant lo Blanch.

25. Merlinsky, G. (2017). "Cartografías del conflicto ambiental en Argentina. Notas teóricometodológicas". Acta Sociológica, 73, pp. 221-246.

26. Pintos, P. (2018). "La cuestión del desarrollo y el extractivismo". En Seminario de posgrado "Paradigmas de desarrollo y la planificación urbana-territorial". Maestría en Estudios Sociales y Culturales. Santa Rosa: FCH-UNLPam.

27. Rojas, F. y Wagner, L. (2016). “Conflicto por la apropiación del río Atuel entre Mendoza y La Pampa (Argentina)". HALAC VI, 2, pp. 278-297.

28. Santos, M. (1990). Por una geografía nueva. Madrid: Espasa Universidad.

29. Santos, M. (1996). De la totalidad al lugar. Barcelona: Oikos Tau.

30. Santos, M. (2000). La naturaleza del espacio. Barcelona: Ariel.

31. Scovenna, J. C. (2012). El caso del río Atuel desde la perspectiva de los derechos humanos. Santa Rosa: Pitanguá.

32. Seoane, J., Taddei, E y Algranati, C. (2013). Extractivismo, despojo y crisis climática. Buenos Aires: Herramienta, El Colectivo.

33. Suárez, F. y Ruggerio, C. (2012). Conflictos ambientales en Argentina-Paradigmas en tensión. Capítulo de libro en: Preciado Coronado, J. Anuario de la integración latinoamericana y caribeña. REDIALC-Universidad de Guadalajara. Recuperado de: http://redcolca.ungs. edu.ar/pdf/Suarez-y-Ruggerio-Conflictos-ambientales-en-Argentina.pdf

34. Svampa, M. (2012). “Consenso de los commodities, giro ecoterritorial y pensamiento crítico en América Latina". Revista del Observatorio Social de América Latina (OSAL). Año XIII, № 32, pp 15-38. Recuperado de: http://biblioteca.clacso.edu.ar/clacso/osal/20120927103642/ OSAL32.pdf

35. Svampa, M. y Viale, E. (2014a). "Continuidad y radicalización del neoextractivismo en la Argentina". Voces en el Fénix, Año 8, № 60, pp. 26-35.

36. Svampa, M. y Viale, E (2014b) Maldesarrollo. La Argentina del extractivismo y el despojo. Buenos Aires: Katz.

37. Universidad Nacional de La Pampa (2005). Estudio para la determinación del caudal mínimo necesario para el restablecimiento del sistema ecológico fluvial en el curso inferior del río Atuel - Informe Final. Santa Rosa. Facultad de Ciencias Exactas y Naturales. Universidad Nacional de La Pampa. 